\title{
Acne Vulgaris among Egyptian Secondary School Adolescents: Prevalence, Complementary Alternative Treatment and Impact on Quality Of Life
}

\author{
${ }^{1}$ Hala M Gabr, ${ }^{2}$ Manal A Al-Batanony, ${ }^{3}$ Shaimaa S Soliman.
}

${ }^{1}$ Public health, Department of Public Health and Community Medicine, Faculty of Medicine, Menoufia University, Egypt. ${ }^{2}$ Department of Family and Community Medicine, Unaizah College of Medicine and Medical Sciences, Qassim University, Kingdom of Saudi Arabia, and Department of Public Health and Community Medicine, Faculty of Medicine, Menoufia University, Egypt, ${ }^{3}$ Department of Public Health and Community Medicine, Faculty of Medicine, Menoufia University, Egypt.

\begin{abstract}
Background: Acne vulgaris is a skin disease of chronic inflammatory nature. Although acne is not a life threatening, it has a deleterious impact on patients' social and psychological health. Objective: to estimate the prevalence of acne among Egyptian adolescents and its effect on their quality of life (QOL) as well as usage of complementary alternative medicine (CAM). Method: A cross-sectional study was conducted on 985 secondary school adolescents. They were asked to fill out a questionnaire including their socio-demographic data and CAM usage information. Their height and body weight were measured to calculate their body mass index (BMI). The Short Form 36 (SF-36) questionnaire was used to assess their quality of life status. Results: The overall prevalence of acne vulgaris was $36.9 \%$ most of them were in mild form (52.3\%). It was not significantly affected by age or type of school. Acne vulgaris was significantly more prevalent among females, those living in urban areas and with low socio-economic status (SES). All the scales of the SF36 QOL questionnaire were significantly lower among participants with acne. About 50\% of those who had acne tried CAM at least once. Honeyyoghurt and yeast face masks were the commonest CAM used without any significant difference between males and females. Conclusion: Acne vulgaris is common among secondary school children and can significantly affect their QOL. Most of them may try CAM at least once. More knowledge on how to deal with and treat acne should be provided to students in this age.
\end{abstract}

Keywords: acne, adolescent, prevalence, alternative medicine, quality of life.

Corresponding author: Shaimaa S Soliman E mails: shaimaasoliman@med.menoufia.edu.eg,

\section{Introduction}

Acne vulgaris is a skin disease characterized by chronic inflammation of the pilosebaceous unit and usually starts during adolescence. It usually affects the face, anterior chest and the upper back. ${ }^{1}$ Severe forms of the disease can be complicated by cysts and scarring. ${ }^{2}$ In general, acne affects mainly teenagers, but sometimes can persist into adulthood. ${ }^{3}$ In the United States of America (USA), acne ranks as the fourth reason for seeking medical care among people aged 11- 21 years, and it accounts for $4 \%$ of all visits from patients aged 15-19 years. ${ }^{4}$ The prevalence of acne among adolescents varies widely. It ranged from $28.9 \%$ to $91.3 \%$ in different studies. $^{5}$

According to the studies carried-out in USA, ${ }^{6}$ Egypt, ${ }^{7}$ Iran, ${ }^{8}$ Kingdom Saudi Arabia (KSA) ${ }^{9}$ and many other countries; acne was proven to have a great effect on the quality of life (QOL) of the affected patients. It can be a cause of anxiety and 
depression in the affected persons. ${ }^{10}$ Acne can also influence patient's prosperity, general and social wellbeing. It may decrease patient's self-confidence and certainly affect mental or cutaneous self-perception, psychological wellbeing, and quality of his/her life. ${ }^{9}$ In general, acne can passively affect the patients' physical and emotional health. ${ }^{11}$ Many modalities have been tried to treat acne all over the world; one of them is Complementary Alternative Medicine (CAM). Patients of acne commonly use home available remedies like honey, yoghurt, apple cider vinegar, cinnamon, egg, papaya, orange, yeast, and lemon. They may also use oils like olive oil, olivera oil, and bourrache oil. Some patients would try nigella sativa (black cumin), zizphus, onions, sulphur soap, vicks vaporub, toothpaste, rose water, rice water, sea water, or mint. ${ }^{12}$

Estimating global prevalence of acne vulgaris is somehow difficult, because information about acne cases depends mainly on self-reporting. This explains why different studies focusing on acne reported a wide range prevalence $(40 \%$ to $95 \%$ ) among adolescents from $12-$ 17 years. $^{3}$

As facial appearance represents an important aspect of one's perception of body image, acne patients usually suffer from psychosocial distress as a result of the disease process. Studies have also shown that acne has serious effects on body image, self-esteem, and socialization. ${ }^{13}$ The affected patients can seek medical and non-medical therapies and spend a lot of money without achieving any significant improvement. ${ }^{14}$

To the best of our knowledge, prevalence of acne was not studied in the Delta region, although it was in Upper Egypt. This work aimed at estimating the prevalence of acne vulgaris among Egyptian adolescents attending secondary schools in Menoufia governorate and studying the effect of acne vulgaris on their quality of life as well as identifying the most common complementary treatments used by them.

\section{Method}

This cross-sectional study was conducted on secondary school students, Menoufia governorate, Egypt from the beginning of November 2017 to the end of April 2018. By using multistage clustering sampling techniques, we selected 985 students as follows: The first stage: Menoufiya governorate contains 9 districts, two districts were chosen by simple random sampling technique (Shebin Al-Kum and Menouf districts). The second stage: Shebin Al-Kum district includes 12 secondary schools (five governmental, one private and six vocational). Additionally, Menouf district contains 8 secondary schools (two governmental, one private and five vocational). By simple random sampling technique, one governmental, one private and one vocational school were chosen from each district. The third stage: As the number of students in each school type is not equal, the sample size was divided on three (vocational, governmental, and private) with a ratio of 5: 3: 1.5 according to stratified random sampling technique. The total eligible participants were 1032; the respondents were 985 (533 students from vocational schools, 300 from governmental schools and 152 from private schools) with a response rate of $95.4 \%$.

Inclusion criteria included: students from the selected schools and classes who agreed to participate. Any student from outside the selected schools or classes or students with chronic skin diseases that can be misdiagnosed as acne (e.g. Rosacea, folliculitis) were excluded. Selected students were informed about the aim of the study as well as the way of answering the questionnaire.

All the enrolled participants were subjected to: A Self-administered questionnaire composed of 3 parts: (a) Demographic data sheet including age, 
gender, residence, educational grade and socio-economic status (SES). SES was calculated using the updated scale by ElGilany et al. The scale consists of 7 domains: Educational and cultural,

Table (1): Prevalence and severity of acne vulgaris among studied participants.

\begin{tabular}{|c|c|c|}
\hline Presence of acne & $\begin{array}{c}\text { Total studied } \\
\text { group } \\
(\mathbf{n = 9 8 5}) \\
\mathbf{N}(\%)\end{array}$ & $95 \% \mathrm{CI}$ \\
\hline Absent & $622(63.1)$ & \\
\hline Prese & 363( & $34.0-39.8$ \\
\hline - Mild $^{\dagger}$ & $190(5$ & 47.4 \\
\hline - Moderate $^{\dagger}$ & $134(36.9)$ & $32.0-41.6$ \\
\hline - Severe S $^{\dagger}$ & $39(10.7)$ & 7.7-13.8 \\
\hline \multicolumn{3}{|c|}{ Proportion from students with acne } \\
\hline $\begin{array}{l}\text { Occupational, } \\
\text { possessions, }\end{array}$ & $\begin{array}{l}\text { Family, } \\
\text { Home }\end{array}$ & $\begin{array}{l}\text { Family } \\
\text { nitations, }\end{array}$ \\
\hline
\end{tabular}

Economic and Health care domain. ${ }^{15}$ (b) Questions about history of using CAM (frequency and type of the substance used). (c) Health-related quality of life data were collected using the Short Form 36 questionnaire in Arabic (SF-36-Ar). ${ }^{16}$ It is a general indicator of the health status and consists of 36 questions divided into 2 main components; physical and mental, with 4 subscales in each one. The rate of each question is from 0 to 100 and the higher the score; the better the level of health. The questionnaires were handled out to the student in their classrooms and they were asked to return the questionnaires back maximally in 2 days.

Weight and height measurements by means of a digital scale after taking off shoes and heavy clothes. Body mass index (BMI) was then calculated by dividing the body weight (in $\mathrm{kg}$ ) by the square height (in meters).

Dermatological examination for diagnosis and grading of acne was done by a paid clinical dermatologist based on Acne Clinical Guidelines by the American Academy of Dermatology 2016. ${ }^{17}$ Participants diagnosed with acne were graded into mild, moderate, and severe according to the criteria made by Feldman et al., 2004. ${ }^{18}$

\section{Ethical Approval}

Respective approval of the Institutional Review Board, Faculty of Medicine, Menoufia University was obtained before starting the study along with all other necessary administrative approvals from Ministry of Education. A written informed consent was signed by each participant and/or his/her parents or legal guardians before being enrolled into the study.

\section{Data management}

Data were coded, tabulated and analyzed using Statistical Package of the Social Science (SPSS) (IBM SPSS statistics for windows, version 22.0, Armnok, NY: IBM Corp.). Data were expressed as mean \pm standard deviation (SD) for quantitative variables and number (No.) and percentage (\%) for qualitative variables. On comparing two groups, student t-test for parametric variables was used. Chi-square test $\left(\chi^{2}\right)$ was used for comparing qualitative data. Multivariate logistic regression analysis models were done to ascertain the effect of possible risk factor on the occurrence of Acne. Two sided P-value $<0.05$ was considered the level of significance.

\section{Results}

The prevalence of acne vulgaris was 36.9\% (363 participants, 95\% CI 34.039.8). Amongst participants with acne; mild form was affecting 190 participants, which was a little bit more than half of the affected participants $(52.3 \%, 95 \%$ CI 47.4-57.3), while moderate form affected 134 participants $(36.9 \%$, 95\% CI $32.0-$ 41.6) and the severe form affected only 39 participants $(10.7 \%, 95 \%$ CI $7.7-13.8)$ (Table 1). 
Hala M Gabr, et al Acne vulgaris among Egyptian secondary school adolescents: prevalence

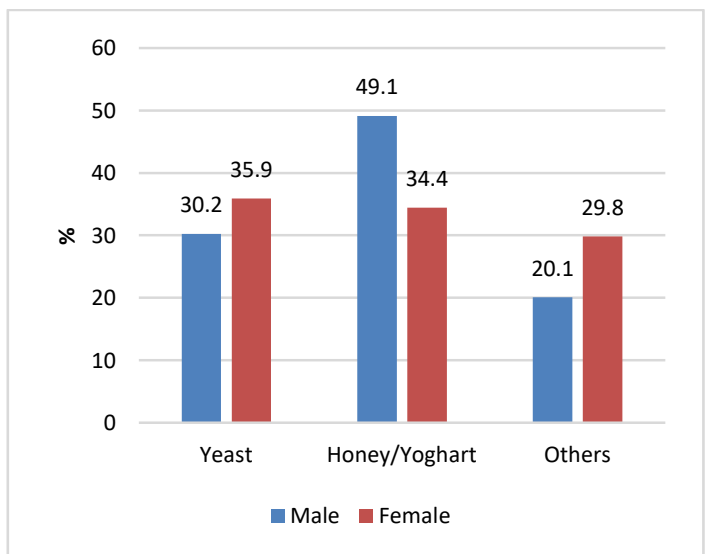

Figure 1: Complementary Alternative Medicine (CAM) among males and females.

Acne vulgaris was significantly more prevalent among females (OR 1.53, 95\%

Table (2): Comparison between participants with and without acne vulgaris regarding sociodemographic characteristics.

\begin{tabular}{|c|c|c|c|c|}
\hline $\begin{array}{l}\text { Socio-demographic } \\
\text { characteristics }\end{array}$ & $\begin{array}{l}\text { With acne } \\
(\mathbf{n}=363)\end{array}$ & $\begin{array}{l}\text { Without acne } \\
\quad(n=622)\end{array}$ & P-value & $\begin{array}{c}\text { OR } \\
(95 \% \mathrm{CI})\end{array}$ \\
\hline Age in years $($ Mean \pm SD $)$ & $17.29 \pm 0.63$ & $17.23 \pm 0.96$ & 0.32 & --- \\
\hline \multicolumn{5}{|l|}{ Gender: No (\%) } \\
\hline - Male* & $144(31.6)$ & $312(68.4)$ & & \\
\hline - Female & $219(41.4)$ & $310(58.6)$ & 0.001 & $1.53(1.18-1.99)$ \\
\hline \multicolumn{5}{|l|}{ BMI category: No (\%) } \\
\hline - Under weight & $23(31.9)$ & $49(68.1)$ & 0.468 & $0.82(0.49-1.39)$ \\
\hline - Normal* $^{*}$ & $204(36.3)$ & $358(63.7)$ & & \\
\hline - Overweight & $68(30.8)$ & $153(69.2)$ & 0.143 & $1.28(0.92-1.79)$ \\
\hline - Obese & $68(52.3)$ & $62(47.7)$ & $<0.001$ & $1.92(1.31-2.83)$ \\
\hline \multicolumn{5}{|l|}{ Residence: No (\%) } \\
\hline - Urban & $230(44.4)$ & $288(55.6)$ & & \\
\hline - Rural* & $133(28.5)$ & $334(71.5)$ & $<0.001$ & $2.01(1.54-2.62)$ \\
\hline \multicolumn{5}{|l|}{ SES: No (\%) } \\
\hline - Low & $118(65.6)$ & $62(34.4)$ & $<0.001$ & $3.57(2.51-5.07)$ \\
\hline - Middle* & $206(34.8)$ & $386(65.2)$ & & \\
\hline - High & $39(18.3)$ & $174(81.7)$ & $<0.001$ & $0.42(0.29-0.62)$ \\
\hline \multicolumn{5}{|l|}{ Type of school: No (\%) } \\
\hline - Governmental* & $102(34.0)$ & $198(66.0)$ & & \\
\hline - Private & $49(32.2)$ & $103(67.8)$ & 0.707 & $0.92(0.61-1.40)$ \\
\hline - Vocational & $212(39.8)$ & $321(60.2)$ & 0.091 & $1.39(0.95-2.03)$ \\
\hline
\end{tabular}

Table 3: Multivariate regression analysis for significant risk factor for Acne vulgaris among the studied group

\begin{tabular}{lccccc} 
& \multicolumn{5}{c}{ Multivariate } \\
\cline { 2 - 6 } \multicolumn{1}{c}{ Variables } & B & P value & Exp (B) & \multicolumn{2}{c}{ 95\% CI } \\
\cline { 5 - 7 } $\begin{array}{l}\text { Gender: } \\
\text { Male* }\end{array}$ & & & & & Upper \\
Female & 0.466 & 0.001 & 1.593 & 1.199 & 2.117 \\
\hline BMI & & & & & \\
Normal* & & 0.025 & & & \\
Underweight & -0.137 & 0.638 & 0.872 & 0.493 & 1.543 \\
Overweight & -0.236 & 0.194 & 0.790 & 0.553 & 1.128 \\
Obese & 0.673 & 0.001 & 1.960 & 1.295 & 2.966 \\
\hline
\end{tabular}




\begin{tabular}{lccccc}
\hline $\begin{array}{l}\text { Residence } \\
\text { Rural* }\end{array}$ & & & & & \\
Urban & 0.692 & $<0.001$ & 1.997 & 1.504 & 2.652 \\
\hline SES & & & & & \\
Middle* & & $<0.001$ & & & \\
Low & 0.185 & $<0.001$ & 3.724 & 2.593 & 5.349 \\
High & 0.202 & $<\mathbf{0 . 0 0 1}$ & 0.435 & 0.293 & 0.646 \\
\hline
\end{tabular}

* Reference category

or multivariate regression analysis (Table $3)$.

Participants with acne had significantly lower scores of all the subscales of the SF36 QOL questionnaire than participants without $(\mathrm{p}<0.001)$ (Table 4). One hundred eighty four participants $(50.7 \%)$ of those who had acne tried

Table (4): Comparison between participants with and without acne vulgaris regarding scales of SF 36 questionnaire.

\begin{tabular}{ll}
\multicolumn{1}{c}{ Scales of SF 36} \\
\hline Physical Functioning \\
\hline Role limitation due to physical problems \\
\hline Bodily pain & 71 \\
\hline General health & 9 \\
\hline Vitality & 7 \\
\hline Social functioning & 68 \\
\hline Role limitation due to emotional problems & 74 \\
\hline Mental health & 73 \\
\hline Discussion &
\end{tabular}

Because acne can be presented clinically in different grades, the prevalence of acne among adolescent can be difficult to assess. Along time ago, authors like Bloch $^{19}$, considered the presence of one comedone is sufficient to diagnose acne. He found an acne prevalence rate of $68.5 \%$ among boys and $59.6 \%$ among girls in a study sample of 4191 subjects. By the end of the twentieth century, Daniel et al., ${ }^{20}$ diagnosed acne by more than 20 inflammatory and rotational lesions, and found a prevalence rate of only $27.9 \%$ among boys and $20.8 \%$ among girls in a study included 914 subjects.

The current study revealed that the prevalence of acne vulgaris among the studied Egyptian secondary school adolescents was $36.9 \%$. This prevalence is very close to a previous study done in Upper Egypt ${ }^{21}$ in Sohag governorate and
CAM at least once. Honey-yoghurt and yeast face masks were the commonest CAM used $(59.2 \%$ and $51.2 \%$; respectively) without any significant difference between males and females in the preferred CAM used (Figure 1).

\begin{tabular}{ccc}
$\begin{array}{c}\text { With acne } \\
(\mathbf{n}=\mathbf{3 6 3}) \\
\text { Mean } \pm \text { SD }\end{array}$ & $\begin{array}{c}\text { Without acne }(\mathbf{n}=622) \\
\text { Mean } \pm \text { SD }\end{array}$ & P-value \\
\hline $85.923 \pm 3.88$ & $88.81 \pm 2.21$ & $<0.001$ \\
\hline $71.47 \pm 11.55$ & $93.65 \pm 2.92$ & $<0.001$ \\
\hline $93.44 \pm 3.33$ & $94.38 \pm 1.29$ & $<0.001$ \\
\hline $74.67 \pm 6.75$ & $89.11 \pm 1.86$ & $<0.001$ \\
\hline $71.47 \pm 7.41$ & $89.32 \pm 1.84$ & $<0.001$ \\
\hline $68.82 \pm 10.15$ & $85.73 \pm 3.20$ & $<0.001$ \\
\hline $74.01 \pm 8.01$ & $87.45 \pm 4.20$ & $<0.001$ \\
\hline $73.29 \pm 7.69$ & $87.47 \pm 3.85$ & $<0.001$ \\
\hline
\end{tabular}

found that the prevalence of acne was $33.5 \%$ among 994 secondary school students. In contrary to our study, Abo El-Fetoh et al., ${ }^{22}$ reported an acne prevalence of $53.5 \%$ among 400 secondary male students in KSA. This higher prevalence in KSA study might be attributed to the older mean age of acne cases which was 21.21 \pm 4.6 . Also, selecting only adolescent male students; which is a cultural issue as well as the difference in the eating habits between Egypt and KSA. The most important risk factors found were consumption of spicy food with excess intake of cola drinks beside genetic predisposition as positive family history.

In Africa, Emeka et al., ${ }^{23}$ in Ibadan, South-west Nigeria detected a prevalence of $64.4 \%$ of acne among adolescents. Higher prevalence could be due to differences in age range, pubertal age and environmental factors. The prevalence in this study was much higher than in 
another study in KSA, which reported only $14.3 \%$ among female secondary school students aged 14-21 years. This might be attributed to the multifactorial nature of the disease and duration of the study where acne cases were measured in three months only in the winter season (from January to March). ${ }^{24}$ It is known that, the skin surface lipid production decreases during winter [25] and there is negative correlation between the skin surface lipid and the incidence of acne. ${ }^{26,27}$

Regarding severity of acne cases, this study found that mild form of acne affected a little bit more than half of the affected participants followed by moderate form and the severe was the least. These results are in accordance with El Hamd et al., ${ }^{21}$ who found that the mild form of acne vulgaris was the most common representing 53\%, followed by moderate form $41 \%$, and severe form 6\%. Also, these results agree with Abo El-Fetoh et al., ${ }^{22}$ where more than half $(54.2 \%)$ of their cases had mild-degree acne. Moreover, most of the individuals in the study done by Durai and Nair ${ }^{28}$, (47.1\%) had mild form of acne. Also, Emeka et al. $^{23}$ reported that mild acne form was the predominant grade among adolescents as well. Comparable figures for Grade I acne were reported by an Indian study ${ }^{13}(60.2 \%)$, a Chinese study ${ }^{29}$ $(68.4 \%)$ and a Saudi study ${ }^{24}(64 \%)$.

In this study, the prevalence of acne vulgaris was significantly more frequent among females $(41.4 \%)$ than males (31.6\%) with OR 1.53 (95\% CI: 1.181.99). The same was reported by El Hamd et al., ${ }^{21}$ where females had acne (60\%) more than males (40\%).

This study demonstrated that $52.3 \%$ of obese participants had acne. This is in accordance with Halvorsen et al., ${ }^{30}$ who found that overweight and obesity were associated with acne in girls aged 18 and 19. Also, Tasi et al stated that boys and girls (age 6-11 years) in Taiwan with lower BMI had a lower prevalence of acne. ${ }^{31}$ Additionally, a significant association between BMI and presence of acne, with a higher prevalence of acne among students with higher BMI was found by a Nigerian's study. ${ }^{23}$

Participants affected with acne in this study had worse quality of life than participants without as shown by having significantly lower scores of all scales of the SF36 QOL questionnaire. Many studies were done to assess the impact of acne on the QOL in different states as Cleveland $^{32}$ or countries like USA ${ }^{33,34}$, Spain $^{35}, \quad \mathrm{UK}^{36}$, $\operatorname{Iran}^{37}$, Malaysia ${ }^{38}$, southern Brazil $^{39}$, and Greece ${ }^{40}$; whereas, studies on Egyptian patients were less frequently reported. These studies used different scales to assess QOL, like Dermatology Life Quality Index (DLQI), Skindex score, the Cardiff Acne Disability Index (CADI) or Acne-QOLI. They all showed negative impact of acne on the QOL of the affected patients.

In this study, 184 participants of those who had acne (50.7\%) tried CAM at least once. Although CAM was used more frequently by females; there with no statistically significant difference between males and female in the overall use of CAM. Most of the affected participants used Honey-yoghurt and yeast face mask as CAM treatment (59.7\% and 51.2\%; respectively). Ahmad et al., ${ }^{12}$ found that honey was the most common CAM type used by $53.4 \%$ of acne patients, followed by yoghurt (43.4\%). A similar finding was in KSA study $^{26}$, which found $35 \%$ of adolescent responders were applying home remedies for acne.

On performing multivariate regression analysis, it was obvious that female gender, urban residence, obesity and low SES were independent risk factors for acne. Other studies found that the most significant associated factors with acne were late adolescent age $^{22,23}$ female gender $^{21}$ and obesity. ${ }^{23,30,31}$

Post Hoc power analysis was done using $\mathrm{G}^{*}$ power. ${ }^{41}$ Prior data indicated that the probability of exposure (effect size) is $0.335{ }^{21}$ Considering $\alpha$ error probability 
is 0.05 and with a total sample size of 985 subjects; the study power would be 1.00 (lower critical $\mathrm{N}$ is 461 , upper critical $\mathrm{N}$ is 524 and actual $\alpha=0.0481$ ).

\section{Conclusion}

Acne vulgaris is a common skin disease among Egyptian adolescents. The prevalence was higher among females and obese adolescents. The affected females tried CAM more than the affected males with no significant difference regarding the type of CAM used. Acne vulgaris negatively affects all aspects of QOL of the affected adolescents. Adolescents should be counseled and health-educated on how to deal with acne vulgaris and other skin diseases. Further studies are recommended to investigate the underlying risk factors and prevalence of acne in Delta region.

Limitations of the study: The crosssectional design made causality interpretation difficult. Also, the study did not include assessment of risk factors such as dietary history, menstrual history, family history and use of topical steroids that could alter the pattern and severity of acne lesions. However, its strength point is including both male and female students, rural and urban residents and narrow age range, so, generalization of results is possible.

Funding: This study receives no funding or financial support.

Authors' contributions: All authors contributed to this project and article equally. All authors read and approved the final manuscript.

Acknowledgments: The authors would like to thank the participants for their cooperation.

Conflict of interest: All the authors have no conflict of interest.

\section{References}

1. Zhang J, Shen $Y$, Wang $T$. et al. Prevalence of Acne Vulgaris in Chinese Adolescents and Adults: A Community- based Study of 17,345 Subjects in Six Cities. Acta Derm Venereol 2012; 92 (1):40-44.

2. Cao H, Liu JP, Luo $H$. et al. Complementary therapies for acne vulgaris (Protocol). Cochrane Database of Syst Rev $2015 ; 19 ; 1$.

3. Williams H, Dellavalle R , Garner S. Acne vulgaris. Lancet.2012; 379: 361-72.

4. Law M, Chuh A, Lee A., Molinari N. Acne prevalence and beyond: acne disability and its predictive factors among Chinese late adolescents in Hong Kong. Clin Exp Dermatol.2010; 35(1):16-21.

5. Purvis D, Robinson E, Watson P. Acne prevalence in secondary school students and their perceived difficulty in accessing acne treatment. N Z Med J. 2004; 20;117(1200):U1018.

6. Taylor A, Pawaskar M, Taylor S, Balkrishnan R. , Feldman S. Prevalence of pigmentary disorders and their impact on quality of life: a prospective cohort study. J Cosmet Dermato. 2008; 7 (3): 164-168.

7. Abdel-Hafez K, Mahran A, Hofny E, Mohammed K. , Darweesh A. The impact of acne vulgaris on the quality of life and psychologic status in patients from Upper Egypt. Int J Dermatol.2009; 48 (3): 280-285. 8. Aghaei S, Sodaifi M, Jafari P, Mazharinia N. , Finlay A. DLQ1 scores in vitiligo: reliability and validity of the Persian version. BMC Dermatol.2004; 4 (8):4-8.

9. Al Robaee A. Assessment of general health and quality of life in patients with acne using a validated generic questionnaire. Acta Dermatovenerol Alp Pannonica Adriat 2009; 18 (4): 157-164.

10. Kaymak Y, Taner E. , Taner Y. Comparison of depression, anxiety and life quality in acne vulgaris patients who were treated with either isotretinoin or topical agents. Int J Dermatol.2009; 48 (1): 41-46.

11. Uhlenhake E, Yentzer B ,Feldman R. Acne vulgaris and depression: a retrospective examination. J Cosmet Dermatol.2010; 9 (1): 59-63.

12. Ahmad A., Alghanemi L., Alrefaie S., Alorabi S., Ahmad G. , Zimmo S. The use of complementary medicine among acne vulgaris patients: Cross sectional study. JDDS.2017; 19 (6), 66-71.

13. Hazarika N, Archana M. The Psychosocial Impact of Acne Vulgaris. Indian J Dermatol. 2016;61(5):515-520. doi:10.4103/0019 5154.190102 
14. Pereira Duquia R, da Silva Dos Santos I, de Almeida H Jr, Martins Souza PR, de Avelar Breunig J, Zouboulis CC. Epidemiology of Acne Vulgaris in 18-YearOld Male Army Conscripts in a South Brazilian City. Dermatology. 2017;233(23):145-154. doi:10.1159/000475775

15. El-Gilany A, El-Wehady A, El-Wasify M. Updating and validation of the socioeconomic status scale for health research in Egypt. East Mediterr Health J. 2012;18(9):962-968.

doi:10.26719/2012.18.9.962

16. Ware J., Kosinski M. , Keller S. SF-36 Physical and Mental Health Summary Scales. a User's Manual. Boston: The Health Institute, New England Medical Center.1994; 21-35.

17. Zaenglein A., Pathy A., Schlosser B., et al. Guidelines of care for the management of acne vulgaris. J Am Acad Dermatol.2016; 74 (5): 945-973.

18. Feldman S, Careccia RE, Barham KL, Hancox J. Diagnosis and Treatment of Acne. Wake Forest University School of Medicine, Winston-Salem, North Carolina. Am Fam Physician. 2004; 69 (9): 21232130.

19. Bloch B. Metabolism, endocrine glands and skin diseases, with special reference to acne vulgaris and xanthoma. $\mathrm{Br} \quad \mathrm{J}$ Dermatol.1931; 43: 77-87.

20. Daniel D, Dréno B, Poli F., et al. Epidémiologie descriptive de l'acné dans la population scolarisée en France métropolitaine pendant l'automne 1996. Ann Dermatol Venereol.2000; 127: 273-278.

21. El-Hamd MA, Nada EEA, Moustafa MA, Mahboob-Allah RA. Prevalence of acne vulgaris and its impact of the quality of life among secondary school-aged adolescents in Sohag Province, Upper Egypt. J Cosmet Dermatol. 2017;16(3):370-373. doi:10.1111/jocd.12328

22. Abo El-Fetoh NM, Alenezi NG, Alshamari NG, Alenezi OG. Epidemiology of acne vulgaris in adolescent male students in Arar, Kingdom of Saudi Arabia. J Egypt Public Health Assoc.2016; 91 (3): 144-149.

23. Emeka O, Adebola O. , Adekunle G. Prevalence and pattern of acne vulgaris among adolescents in Ibadan, south-west Nigeria. J Egypt Women Dermatol Soc. 2016; 13 (1): 7-12.
24. Alanazi MS, Hammad SM, Amal Elwan Mohamed AE. Prevalence and psychological impact of Acne vulgaris among female secondary school students in Arar city, Saudi Arabia, in 2018. Electronic Physician. 2018, 10, (8): 7224-7229.DOI: 10.19082/7224

25. Meyer K, Pappas A, Dunn K, Cula GO, Seo I, Ruvolo E, et al. Evaluation of seasonal changes in facial skin with and without acne. J Drugs Dermatol. 2015; 14: 593-601. PMID: 26091385.

26. Ikaraoha CI, Taylor GO, Anetor JI, Onuegbu JA. Pattern of skin surface lipids in some south-western nigerians with acne vulgaris. West Afr J Med. 2004; 23: 65-8. doi: $\quad 10.4314 /$ wajm.v23i1.28086. PMID:15171531.

27. Shengjie L, Zhang Y, Zheng G, et al. Investigation and analysis of sick status and influencing factors on the undergraduates facial acne vulgaris in Taian. Chin $J$ Dermato-venereol. 2012; 26: 625-7.

28. Durai P , Nair D. Acne Vulgaris and Quality of Life Among Young Adults in South India. Indian J Dermatol.2015; 60 (1): 33-40.

29. Shen Y, Wang T, Zhou C, Wang X, Ding $X$, Tian S, et al. Prevalence of Acne Vulgaris in Chinese Adolescents and Adults: A Community-based Study of 17,345 Subjects in Six Cities. Acta Derm Venereol. 2012; 92: 40-4. doi: 10.2340/00015555-1164. PMID: 21710106.

30. Halvorsen JA, Vleugels RA, Bjertness E, Lien L. A population-based study of acne and body mass index in adolescents. Arch Dermatol. 2012;148(1):131-132. doi:10.1001/archderm.148.1.131

31. Sai MC, Chen W, Cheng YW, Wang CY, Chen GY, Hsu TJ. Higher body mass index is a significant risk factor for acne formation in school children. Eur $\mathrm{J}$ Dermatol. 2006;16(3):251-253

32. Lasek R, Chre M. Acne vulgaris and the quality of life of adult dermatology patients. Arch Dermatol. 1998;134: 454458.

33. Rapp S, Feldman S, Graham G, Fleischer A. , Brenes G. The Acne Quality of Life Index (Acne-QOLI). Development and validation of a brief instrument; Am J Clin Dermatol. 2006; 7: 185-92.

34. Rapp D, Brenes G, Feldman S. et al. Anger and acne: Implications for quality of life, patient satisfaction and clinical care. $\mathrm{Br}$ J Dermatol. 2004; 151:183-9. 
35. Jones-Caballero M, Chren M, Soler B, Pedrosa E, Penas P. Quality of life in mild to moderate acne: Relationship to clinical severity and factors influencing change with treatment. J Eur Acad Dermatol Venereol. 2007; 21: 219-226.

36. Walker N , Lewis-Jones M. Quality of life and acne in Scottish adolescent school children: Use of the Children's Dermatology Life Quality Index (CDLQI) and the Cardiff Acne Disability Index (CADI). J Eur Acad Dermatol Venereol. 2006; 20: 45-50.

37. Aghaei S, Mazharinia N, Jafari P, Abbasfard Z. The Persian version of the Cardiff Acne Disability Index. Reliability and validity study. Saudi Med J. 2006; 27 : 80-82.

38. Hanisah A, Omar K, Shah S. Prevalence of acne and its impact on the quality of life in school-aged adolescents in Malaysia. J Prim Health Care.2009; 1: 20-25.

39. Tejada CDS S, Mendoza-Sassi R, Almeida H, Jr Figueiredo P, Tejada V. Impact on the quality of life of dermatological patients in southern Brazil. An Bras Dermatol.2011; 86: 111321.

40. Tasoula E, Gregoriou S, Chalikias J. et al. The impact of acne vulgaris on quality of life and psychic health in young adolescents in Greece, Results of a population survey. An Bras Dermatol.2012; 87: 862869.

41. Faul, F., Erdfelder, E., Lang, A.-G., \& Buchner, A.. G*Power 3: A flexible statistical power analysis program for the social, behavioral, and biomedical sciences. Behavior Research Methods, 2007; 39, 175-191 